\title{
Informing Mexico's Distributed Generation Policy with System Advisor Model (SAM) Analysis
}

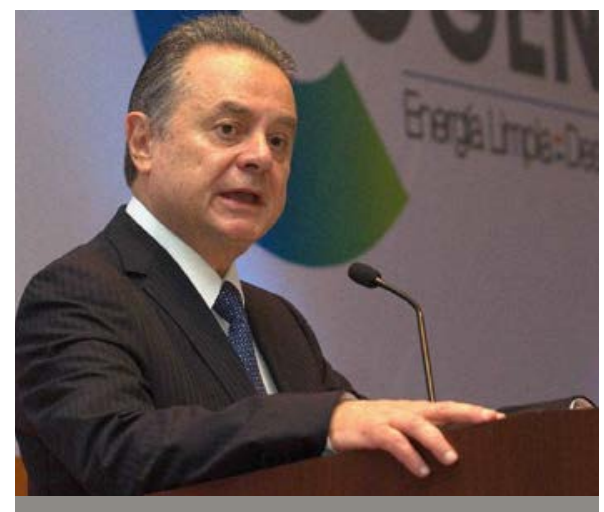

Figure 1. Mexico Secretary of Energy Pedro Joaquín Coldwell presenting the benefits of distributed photovoltaic (DPV) systems at the release of SENER's "Beneficios de la Generacion Limpia Distribuida y la Eficiencia Energetica en Mexico" report. (Photo from cronica.com)

\section{The Mexican government} aims to generate $35 \%$ of its electricity from clean energy by 2024 as part of its comprehensive strategy to reduce carbon emissions and address climate change.

Similarly, Mexico has committed to a $22 \%$ reduction in greenhouse gas emissions by 2030 according to their Nationally Determined Contribution (NDC). In December 2015, Mexico passed the Energy Transition Law, which provides a legal framework for a variety of actions that will help Mexico achieve its clean energy deployment and emissions reductions goals. The law regulates the sustainable use of energy, articulates the electric industry's obligations regarding Mexico's clean energy targets, and establishes a tradeable clean energy certificate system for meeting clean energy targets.
The Government of Mexico (GOM) has recognized the potential for clean distributed generation (DG) to meaningfully contribute to Mexico's clean energy and NDC goals. Passage of the Energy Transition Law has created a unique moment in Mexican history to set policy, regulations, and technical procedures to encourage the growth of the DG market in Mexico. However, important questions remain about how to fairly value DG and foster inclusive and equitable market growth that is beneficial to investors, electricity ratepayers, electricity distributors, and society.

The U.S. National Renewable Energy Laboratory (NREL) has partnered with power sector institutions and stakeholders in Mexico to provide timely analytical support and expertise to help inform policymaking processes on clean DG. This document describes two technical assistance interventions that used the System Advisor Model (SAM) to inform the DG policymaking processes for GOM throughout 2016, with a focus on rooftop solar regulation and policy. These technical assistance interventions were conducted by NREL experts - in close collaboration with staff from various GOM departments - under the U.S. Agency for International Development (USAID) Mexico Clean Energy Program.

The following sections briefly describe relevant contextual aspects of national energy policy, as well as the analysis process, key findings, and impacts. Both analytical exercises described in this report used NREL's SAM model, which can examine the technical and economic performance of distributed solar systems (see Using the System Advisor Model for Distributed Photovoltaic Analysis in Mexico). Thus, some additional detail will be provided about how the SAM model was used in these analyses to provide credible, science-based estimates to inform public policy.
Informing Mexico's Rooftop Solar Compensation Policy with the Energy Regulatory Commission

The first analysis described in this document was conducted with the Energy Regulatory Commission of Mexico (CRE) between July and September of 2016; it was designed to inform internal discussions at CRE, focusing on how customers might be impacted by prospective changes to DG metering \& billing arrangements in Mexico. The results of this analysis were used to inform an update to Mexico's DG regulatory framework released in February 2017.

\section{A Multiperspective Quantification of Benefits of Rooftop} Solar in Mexico with the Secretariat of Energy The second analysis described in this document was conducted under the leadership of Mexico's Secretariat of Energy (SENER), analyzing the potential benefits of residential sector DG and energy efficiency from the perspectives of (a) individual customers, (b) the Mexican Secretariat of Finance and Public Credit, and (c) the environment. The analysis process began in July of 2016 and concluded with the publishing of the analysis report in December 2016. 


\section{Using the System Advisor Model for Distributed Photovoltaic Analysis in Mexico}

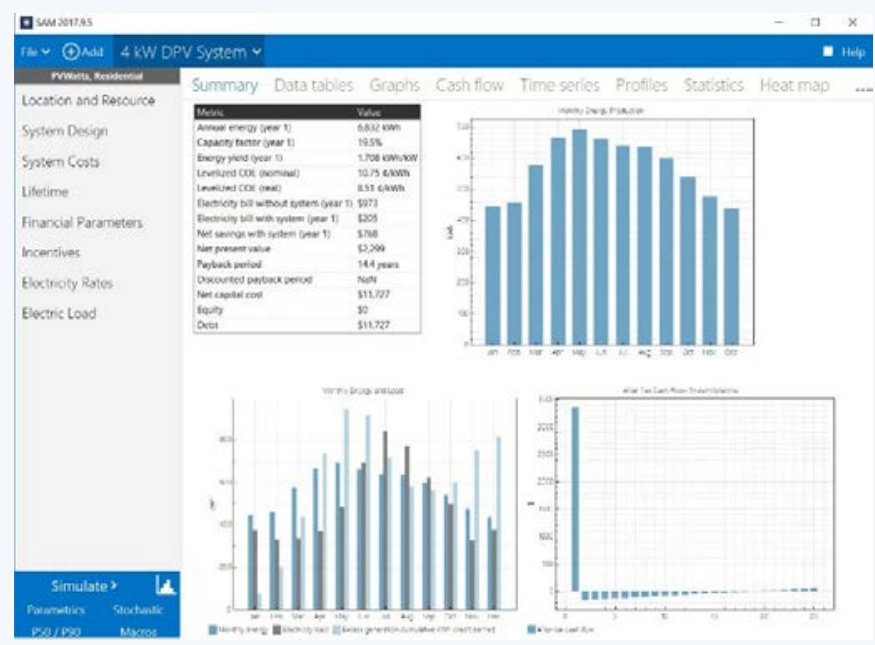

SAM is a free state-of-the-art software for simulating the performance and economics of renewable energy projects. SAM creates technical performance predictions, levelized cost of energy estimates, cash flow calculations, and a range of other quantitative metrics for grid-connected power projects based on costs and system design parameters specified by the user. Projects can either be simulated from the customer side of the meter-buying and selling electricity at specified rates, or from the project developer standpoint-selling electricity at a price negotiated through a power purchase agreement. The tool is developed and maintained by NREL and is available for download at no cost from: https://sam.nrel.gov.

Among other renewable energy technologies, SAM offers a user-friendly, detailed treatment of distributed photovoltaic (DPV), including rooftop solar systems. The model takes into account customer consumption patterns, retail electricity rates, DPV compensation schemes, system pricing, and a variety of other technical and economic inputs. It can be used to create hourly generation profiles for rooftop solar projects, perform payback period or return-on-investment analyses, or test the impact of various DPV public policies on customer economics. In 2016, SAM was adapted to perform DPV analyses in Mexico via (1) adaptation of high-fidelity Mexican weather data from the National Solar Radiation Data Base and (2) inclusion of Mexican retail electricity tariffs in the OpenEI U.S. Utility Rate Database. These important upgrades now allow for users to quickly and easily design Mexican cases.

In December 2017, a sample Mexican case file was developed to enable additional Mexico-specific solar analysis by other entities. A Spanish language webinar demonstration of SAM is available here.

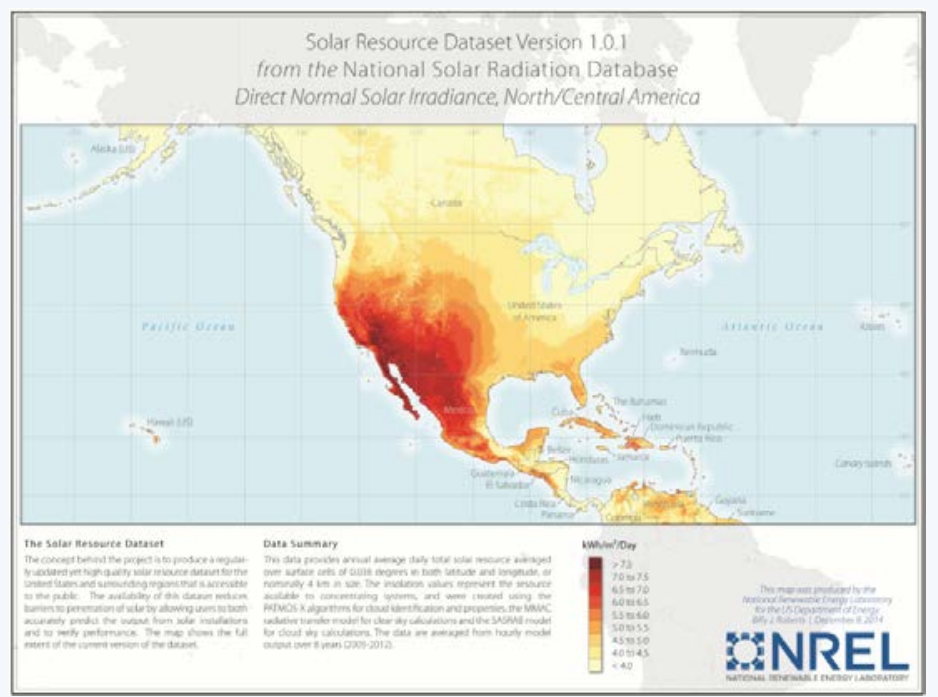

\section{INFORMING MEXICO'S ROOFTOP SOLAR COMPENSATION POLICY WITH THE CRE}

Context: CRE is the national energy regulator in Mexico, responsible for designing, implementing, and enforcing a range of economic and technical regulations in the electricity, oil and natural gas sectors. Within this capacity, CRE defines how owners of DG systems are compensated for the electricity they produce. They have purview to modify DG metering and billing arrangements, retail rates, and DG sell rates.

Under the December 2015 Energy Transition Law, CRE was given a legal obligation to offer a compensation scheme for DG that reflected the value of the resource. CRE was thus interested in exploring the various options at their disposal to comply with the
Table 1. Primary Mechanisms for CRE to Influence DG Customer Compensation. For More Information on the Terms in this Table, See Zinaman et al. (2017).

\section{How can CRE influence DG customer compensation?}

\begin{tabular}{|l|l}
\hline $\begin{array}{c}\text { Metering \& Billing } \\
\text { Arrangements }\end{array}$ & $\begin{array}{l}\text { CRE defines how consumption- and generation-related electricity } \\
\text { flows are measured and billed. Common options including Net } \\
\text { Energy Metering (NEM), Net Billing (NB), and Buy-all, Sell-all } \\
\text { (BASA). }\end{array}$ \\
\hline Sell Rate Design & $\begin{array}{l}\text { CRE defines the exact level of compensation a DG system owner } \\
\text { receives for electricity exported from the DG system to the utility } \\
\text { grid, and also sets the conditions under which customers are } \\
\text { provided with credits and/or cash payments for their exports. }\end{array}$ \\
\hline Retail Rate Design & $\begin{array}{l}\text { CRE defines changes to retail rates for customers who install DG } \\
\text { systems, and also to retail rates more broadly which may have } \\
\text { financial implications for DG owners under Net Energy Metering } \\
\text { and Net Billing arrangements. }\end{array}$ \\
\hline &
\end{tabular}


law, while also ensuring the health of the nascent rooftop solar market in Mexico.

Analysis Question: Through a series of discussions with NREL in the Summer of 2016, the Clean Energy Regulation unit at CRE decided to explore how three different options for metering and billing arrangements would impact the economics of DPV for customers in Mexico.

\section{High-level Analysis Question \\ What are the relative economics of three potential compensation mechanism schemes for residential customers in Mexico?}

The next step was to translate this into an answerable and concrete analysis question, with an emphasis on selecting an expedient approach, given that the rest of the regulatory framework development process - including establishing rules governing interconnection, ownership, and equipment requirements — was moving forward with great speed. CRE also expressed a particular interest in exploring how to incorporate locational marginal prices (LMPs) from the recently launched Mexican wholesale energy market into DG customer compensation schemes, as this could be a useful construct to comply with their legal obligation to provide a value-based compensation scheme.

Because it is not possible to model all customers in all locations in Mexico, the analysis team encountered a key challenge of many DPV analyses: formulating credible, average DPV customers for which results could be simulated and understood to yield broader policy insights (see The Importance of Formulating Credible Average Customers in DPV Policy Analyses). In partnership with CRE, the team decided to simulate low-use and high-use residential customers in the cities of Tijuana, Monterrey, Guadalajara, Merida, and Mexico City. These cities were selected because of their diverse weather patterns and distinct levels of wholesale market pricing. The total number of DPV customers modeled in the analysis came to 30 , to accommodate three compensation mechanisms, five locations, and two types of consumption levels with corresponding tariffs.

Modeled compensation mechanisms (CM) for the analysis are described in Table 2. Note that CM \#1 reflects a baseline/business as usual policy.

\section{Key Data Needs and Assumptions:}

Constructing individual DPV customers required a range of input data and assumptions. The team used monthly average customer consumption data from the electric utility, Federal Electricity Commission (CFE), and descriptions of retail rates from CRE. The SAM model's standard technical assumptions for DPV systems were used for the sake of analytical simplicity. For each modeled customer, DPV systems were sized to produce a quantity of energy equal to $100 \%$ of the customer's annual consumption.

Two types of data proved quite difficult to acquire for Mexico. The first - which is often difficult to acquire in early-stage DPV markets - were credible estimates of DPV system costs. Here, a value was ultimately formulated through informal conversations with solar developers and other industry stakeholders in Mexico. The second type of data that was difficult to acquire was hourly customer consumption data. This is particularly important when examining the economics of Net Billing policies because under these schemes grid injections are immediately converted into bill credit (as opposed to kilowatt-hour credits under NEM). For these data, the SAM model's endogenous load profile calculator was used, based on local weather data and typical Mexican household characteristics.
Results: The team performed a simple payback period analysis using NREL's SAM model for 30 DPV customers, with results shown in Table 3.

Overall, it was found that if the current policy were shifted to $\mathrm{CM} \# 2$, prospective residential DPV customers may see their value proposition decrease between $6 \%$ and $35 \%$ in terms of simple payback period. If customers were required to enroll in $\mathrm{CM} \# 3$ - sending all DPV production to the grid at corresponding hourly LMP, payback periods in some cases could more than double.

Impact: The results of this analysis were presented at several cross-departmental internal meetings at CRE. After elucidating the extent of the reduced DPV value proposition of shifting to market-based compensation schemes, CRE decided to offer CM \#2 and CM \#3 as options for customers while maintaining CM \#1, which enabled compliance with the Energy Transition Law. Given the nascence of the Mexican DPV market and the lack of significant deployment to-date, $\mathrm{CRE}$ also decided to augment the existing CM \#1 to compensate customers for expired kilowatt-hour credits at the market rate for energy. Previously the customer forfeited these to the utility without compensation. In February 2017, these changes were codified in the "Manual for Interconnection of Generation Centers with a Capacity Under 0.5 MW" (CRE 2017).

Table 2. Three Modeled Compensation Mechanisms

\begin{tabular}{|c|c|c|c|}
\hline & M\&B & Sell Rate & Retail Rate* \\
\hline CM \#1 & $\begin{array}{c}\text { Net Energy Metering } \\
\text { (NEM) }\end{array}$ & $\begin{array}{c}\text { No compensation for net } \\
\text { excess generation }\end{array}$ & $\begin{array}{c}\text { Low Consumption } \\
\text { Customers: } \\
\text { Tariff 1 or 1C }\end{array}$ \\
\hline $\mathbf{C M ~ \# 2}$ & $\begin{array}{c}\text { Net Billing } \\
\text { (NB) }\end{array}$ & $\begin{array}{c}\text { Real-time LMP for all } \\
\text { grid injections }\end{array}$ & $\begin{array}{c}\text { High Consumption } \\
\text { Customers: }\end{array}$ \\
\hline $\mathbf{C M ~ \# 3}$ & $\begin{array}{c}\text { Buy-all, Sell-all } \\
\text { (BASA) }\end{array}$ & $\begin{array}{c}\text { Real-time LMP for all } \\
\text { production }\end{array}$ & \begin{tabular}{c} 
Tariff DAC \\
\hline
\end{tabular} \\
\hline
\end{tabular}

*In Mexico, not all residential tariffs are available in all locations, and customers may be placed in different rate classes based on their consumption. Thus, the low-consumption retail rate displayed in Table 2 may change based on the city, and distinct tariffs are assumed for low- and high-consumption residential customers.

Table 3. Payback Period Analysis Results [Years] by Customer Consumption, Location, and Compensation Mechanism

\begin{tabular}{|c|c|c|c|c|c|c|}
\hline & \multicolumn{3}{|c|}{ Low Use } & \multicolumn{3}{c|}{ High Use } \\
\hline & \#1 NEM & \#2 NB & \#3 BASA & \#1 NEM & \#2 NB & \#3 BASA \\
\hline TIJ & 14 & 19 & 27 & 10 & 13 & 27 \\
\hline MON & 16 & 20 & 24 & 14 & 16 & 24 \\
\hline GUAD & 13 & 15 & 17 & 9 & 10 & 17 \\
\hline MER & 16 & 17 & 18 & 14 & 15 & 18 \\
\hline CDMX & 13 & 16 & 19 & 11 & 12 & 19 \\
\hline
\end{tabular}




\section{The Importance of Formulating Credible Average Customers in DPV Policy Analyses}

DPV markets comprise a multitude of individual customers who have made a personal decision to invest in a solar system for their home or business. All customers are unique with respect to how much electricity they consume, where they are located, the cost, size, and performance of their DPV system, and a variety of other important characteristics.

Because it is impossible to simulate impacts of changes to DPV policy on all possible customers—and absent sophisticated market adoption forecasting tools such as NREL's dGen Model (see Sigrin et al. 2016)—it is important to design DPV customers who exhibit average characteristics and are statistically representative of the larger pool of potential DPV customers. In doing so, broader insights might be yielded about the potential impact of a particular policy change on the DPV market, or on a certain segment of impacted customers. While creating average customers is by no means a perfect approach, it is nevertheless a useful construct to gain insights into broader policy impacts.

The individual DPV customers modeled by an analysis serve as the cornerstone of any DPV policy analysis study.

- The analysis described in this section formulated individual residential customers designed to represent the broader residential DPV market in Mexico, such that the shifting economics of residential DPV investment because of changes in regulation could be better understood.

- In a different study (Tongsopit et al. 2017), analysts formulated representative residential, commercial, and industrial DPV customers across a multitude of locations in Thailand. The analysis then scales the financial impacts of those DPV customers on Thai distribution utilities for 3,000 MW of DPV.

\section{A MULTIPERSPECTIVE QUANTIFICATION OF BENEFITS OF ROOFTOP SOLAR IN MEXICO}

Context: SENER is the primary GOM department responsible for formulation and implementation of national energy policy. Under the December 2015 Energy Transition Law, SENER had a statutory obligation to study the benefits of clean DG and energy efficiency for residential customers.

The Secretariat, with the support of a national research center, and within 365 days of the promulgation of this law, must conduct a first analysis on: a) possible savings for the State, b) savings for users, and c) the reduction of the carbon footprint derived from the installation of clean distributed generation technologies and various energy efficiency measures for residential users, in terms of article 10 , fraction $\mathrm{V}$, of the Energy Transition Law.

Analysis Question: Under SENER's leadership, a multi-institutional analysis team was assembled to conduct the study. The effort included a broad community of stakeholders, including participants from $\mathrm{CRE}, \mathrm{CFE}$, the German Corporation for International Cooperation, the Mexican Climate Initiative, and various Mexican universities. In February
2016, a one-day charrette was hosted by SENER and the Center for Economic Research and Training in Mexico City. The charrette focused on the distributed solar aspect of the law, identifying relevant analysis methodologies, defining which specific benefits would be quantified, and formulating a list of data requirements from various institutions.

Following an extensive discussion of available data sets, tools, and analytical approaches, the charrette yielded specific, desired analysis outputs, which are described in Table 4.

Table 4. SENER DPV Benefits Analysis Output

\begin{tabular}{|c|c|}
\hline \multicolumn{2}{|r|}{ What outputs did the analysis produce? } \\
\hline $\begin{array}{c}\text { State } \\
\text { Perspective }\end{array}$ & $\begin{array}{l}\text { - Avoided annual subsidy payment by GOM per kilowatt of installed } \\
\text { DPV for the seven subsidized residential customer classes in three } \\
\text { most populous cities in each of the } 16 \text { tariff geographic divisions in } \\
\text { Mexico under the current NEM policy framework }\end{array}$ \\
\hline $\begin{array}{l}\text { Customer } \\
\text { Perspective }\end{array}$ & $\begin{array}{l}\text { - Annual customer bill savings per kilowatt of installed DPV for seven } \\
\text { subsidized residential customer classes in three most populous cities } \\
\text { of each of the } 16 \text { tariff divisions in Mexico under the current NEM } \\
\text { policy framework } \\
\text { - Payback period of DPV system sized to meet } 100 \% \text { of annual } \\
\text { consumption and priced at MXN } \$ 35 / \mathrm{W} \text { for seven average subsidized } \\
\text { residential customer classes in three most populous cities of each of } \\
\text { the } 16 \text { tariff geographic divisions in Mexico under the current NEM } \\
\text { policy framework }\end{array}$ \\
\hline $\begin{array}{l}\text { Environmental } \\
\text { Perspective }\end{array}$ & $\begin{array}{l}\text { - Avoided annual } \mathrm{CO}_{2}, \mathrm{NOx} \text {, and } \mathrm{SO}_{2} \text { emissions per } \mathrm{kW} \text { of installed } \\
\mathrm{DPV} \text { for three most populous cities in each of the } 16 \text { tariff geographic } \\
\text { divisions in Mexico [ } 48 \text { cases] } \\
\text { - Avoided annual water use from fossil fuel power plants per } \mathrm{kW} \text { of } \\
\text { installed DPV for three most populous cities in each of the } 16 \text { tariff } \\
\text { geographic divisions in Mexico }\end{array}$ \\
\hline
\end{tabular}

High-level Analysis Question

What are the benefits of distributed solar to residential customers, the Government of Mexico, and the environment?

The total number of DPV customers modeled in the analysis was 336 , accommodating seven residential customer classes, 16 geographic tariff divisions, and three cities per tariff division. SAM was selected as the tool to simulate these DPV customers. 


\section{Results and Outcomes}

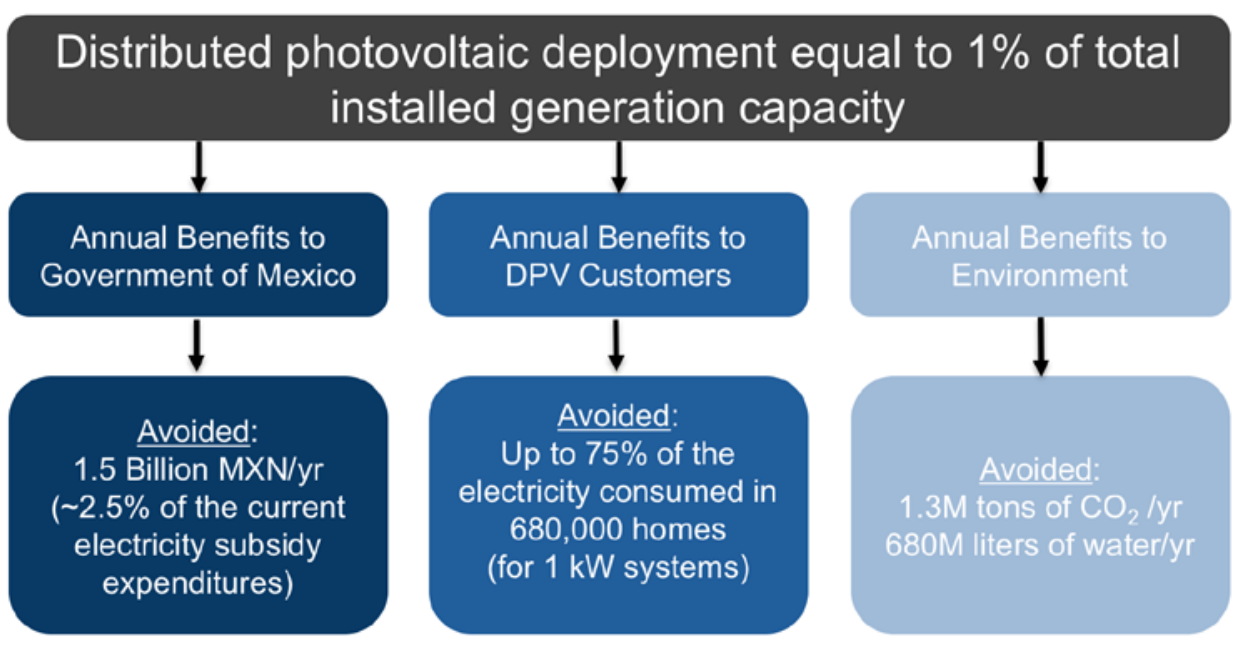

Figure 2. Benefits associated with a 1\% DPV penetration on a capacity basis for the State, DPV Customers, and the Environment. Adapted from SENER 2017.

\section{Key Data Needs and Assumptions:}

Among the core challenges of this analysis was accurately characterizing Mexico's complex system of residential tariffs that have distinct winter and summer inclining block energy tariffs and change based on temperature zone and month. Residential tariff structures also feature distinct minimum bill charges or fixed charges. Thus, upfront engagement with CRE to clarify these tariff design aspects was an important step to ensuring an accurate representation of tariffs.

The analysis team also had to acquire confidential rate subsidy information from the Mexican Secretariat of Finance and Public Credit which changed for each of the seven subsidized residential customer classes. In addition, average monthly load data were acquired from CFE for each residential customer classes in each of Mexico's 16 geographic tariff divisions.

As a result of the nascent state of the DPV market in Mexico, reliable DPV cost data were not available. Thus, a cost of $\$ 35$

MXN/W was assumed for DPV systems based on informal discussions with solar developers.
Because of a lack of hourly wholesale market data, simplified assumptions were made about environmental benefits. Specifically, they were calculated based on the average emissions and water intensity of the Mexican power generation fleet in 2015 .

Results: The team formulated a programming script in SAM to handle the large number of customer cases that were modeled for the analysis. With such a large number of cases, the results were quite detailed and extensive, and the analysis yielded many insights for SENER.

For the DPV customer perspective, the analysis found that while the annual bill savings associated with deploying DPV may be attractive for subsidized residential customer classes, these customers were not likely to install DPV without a substantial policy intervention, given the economics of the investment. Under the assumptions put forth in the analysis, simple payback period estimates for DPV systems ranged from 15 to 26 years, with a mean value of 21 years. By comparison, high-use residential customers paying a significantly higher rate under the
Table 5. Payback period results (all locations) by Mexican tariff class

\begin{tabular}{|c|c|c|c|c|c|c|c|c|}
\hline & $\mathbf{1}$ & $\mathbf{1 a}$ & $\mathbf{1 b}$ & $\mathbf{1 c}$ & $\mathbf{1 d}$ & $\mathbf{1 e}$ & $\mathbf{1 f}$ & $\mathbf{D A C}$ \\
\hline Min. & 21 & 17 & 18 & 16 & 16 & 16 & 15 & 4.5 \\
\hline Avg. & 22 & 22 & 21 & 19 & 20 & 18 & 16 & 5.1 \\
\hline Max & 26 & 27 & 26 & 22 & 27 & 21 & 17 & 6.0 \\
\hline
\end{tabular}

\section{What benefit does DPV offer the GOM?}

As a matter of social and economic policy, the GOM directly subsidizes retail electricity tariffs for certain customer segments throughout the country, including lower consumption residential customers, agricultural customers, and regulated industrial customers. These subsidy payments are a significant national budgetary expenditure. If these customers install DPV systems, they will purchase a lower volume of subsidized electricity from the basic supplier CFE, which will reduce the GOM's annual expenditures on electricity subsidies for that customer without the customer experiencing any form of bill increase. However, it is also important to note that the GOM collects an $18 \%$ sales tax on electricity bills, so the GOM benefit associated with lower electricity sales is a net benefit.

DAC tariff (which is used to subsidize other customers) were experiencing payback periods of 5-6 years.

From the State perspective, the potential benefits of avoided subsidy payments from DPV deployment changed substantially based on tariff class and location. Under the assumptions put forth in the analysis, DPV deployment by subsidized residential customers yielded an average of MXN \$2,221 per installed kilowatt of DPV per year for the State but ranged from approximately MXN \$1,500 to $\$ 3,000$. Specific regions and customer classes with the highest subsidy reduction potential were also identified, which can be used to inform the location of potential pilot programs for providing an upfront subsidy for DPV systems. A summary of analysis results is depicted in Figure 2.

Impact: Perhaps most significantly, the analysis uncovered that there is a substantial disconnect between where the highest potential benefits exist for the State, versus where it is most financially attractive for customers to invest in DPV systems. From the analysis, SENER concluded that without a public policy intervention, DPV's “penetration in the market will be very slow, and 
the environmental and social benefits will not be observed in the short- and medium-term." However, the value proposition to the GOM for a public policy intervention was also made quite clear.

A report summarizing the findings was released in January of 2017 by Mexico Secretary of Energy Joaquin Coldwell.

"A well-supported public policy can be a bridge between benefits for the Federal Government and for users." (SENER 2017)

Written by Owen Zinaman, Alexandra Aznar, and James McCall, Clean Energy Transition Partners, LLC, and National Renewable Energy Laboratory.

\section{Jeff Haeni}

U.S. Agency for International Development Energy Division, Office of Energy \&

Infrastructure Programs

Tel: +1-202-712-0546

Email: jhaeni@usaid.gov

\section{Alexandra Aznar}

National Renewable Energy Laboratory

Tel: +1-303-275-3224

Email: alexandra.aznar@nrel.gov

The Distributed Photovoltaics Toolkit is part of the Greening the Grid technical platform, which addresses the technical challenges around grid modernization and state-of-the-art practices in bringing advanced energy technologies into the power sector. Greening the Grid is supported by the U.S. Agency for International Development.

\section{USAID RNREL}

greeningthegrid.org

nrel.gov/usaid-partnership

NREL is a national laboratory of the U.S. Department of Energy, Office of Energy Efficiency \& Renewable Energy, operated by the Alliance for Sustainable Energy, LLC.

Contract No. AEG-P-00-09-00003-00

NREL/TP-7A40-71038 • May 2018

\section{MORE INFORMATION REGARDING THE USAID DISTRIBUTED PHOTOVOLTAIC PROGRAM}

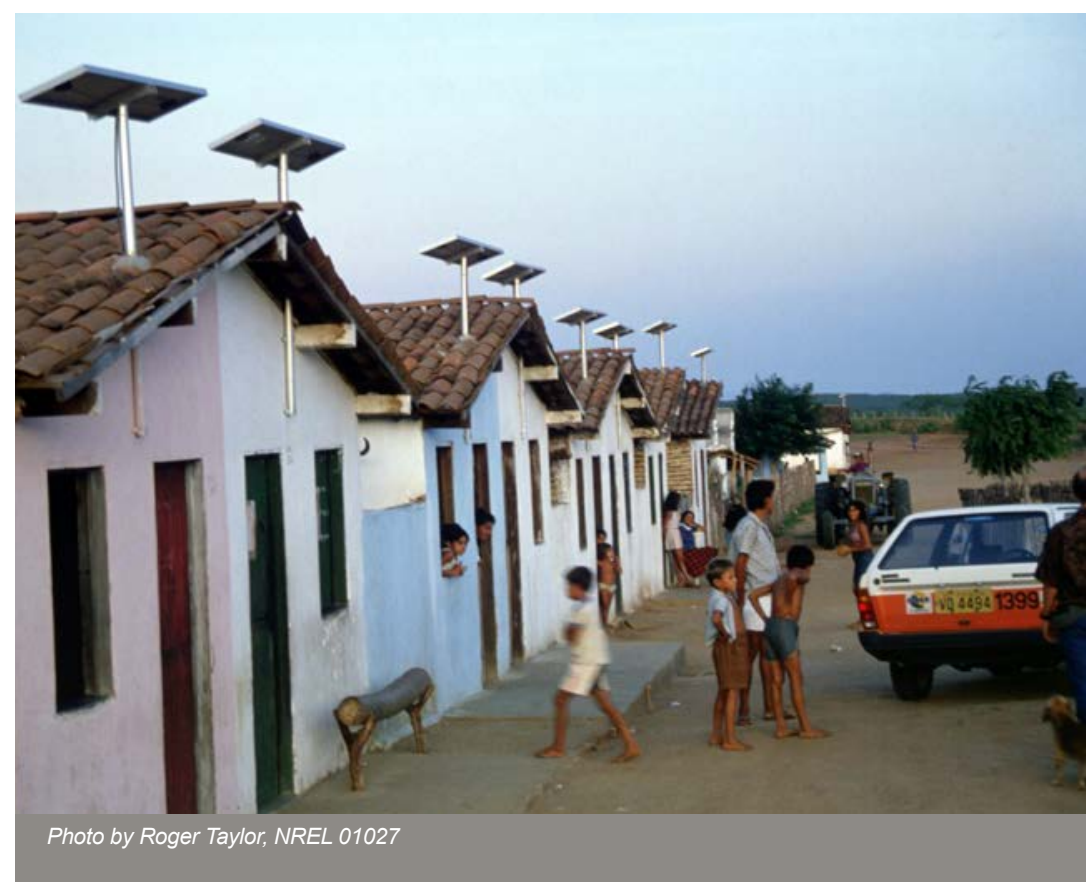

The USAID Distributed Photovoltaic Program

Accelerating Deployment of Distributed Photovoltaics in Partner Countries

Website: http://greeningthegrid.org/integration-in-depth/distributed-generation

This USAID Energy Division Distributed Photovoltaic (DPV) Program builds capacity in partner countries through pilot projects and technical assistance in support of DPV deployment. The U.S. National Renewable Energy Laboratory (NREL) is the Operating Agent of this program, bringing stateof-the-art analytics and international best practices to activities that carefully target the specific needs and conditions of individual country contexts.

Ongoing and past projects include technical assistance work in Mexico, Ghana, Colombia, Jamaica, and Thailand. The NREL team works regularly with utilities, regulators and government ministries, taking a holistic approach to technical assistance and capacity-building. Specific DPV topics covered under the program include (but are not limited to):

- DPV Compensation Mechanism Design

- Grid Codes, Equipment Standards, and Interconnection Processes

- Distributed Solar Economic Impact Analysis

- Public Policy Formulation and Augmentation (incl. Incentive Programs and Tariff Design)

- Mitigation of Legal and Institutional Barriers to DPV Deployment

- Incorporation of DPV into Utility Planning

- DPV Technical Impact Mitigation Strategies for Utilities. 